\title{
About the Territorial Potential of the Construction of Battery-Charging Stations for Autonomous Electric Motor Vehicles in the Regions
}

\author{
Lyubov Shilova ${ }^{1, *}$, Dmitry Soloviev ${ }^{2}$, Vassily Timatkov ${ }^{2}$, and Aleksey Adamtsevich ${ }^{1}$ \\ ${ }^{1}$ Moscow State University of Civil Engineering, 129337 Yaroslavskoe sh. 26, Moscow, Russia \\ ${ }^{2}$ Joint Institute for High Temperatures of the Russian Academy of Sciences, 125412 Izhorskaya str. \\ 13/2, Moscow, Russia
}

\begin{abstract}
The article describes the main current trends in the development of electric motor vehicles with "zero emission" as well as the battery-charging stations concerned. The study is based on a preliminary comparative analysis of the RF regions with respect to five indices (average per capita income, number of private cars in the region, air pollution level, provision of the region with power supply and the potential use of local renewable energy resources), and it gives some recommendations on the prospects of possible construction of batterycharging stations in the regions.
\end{abstract}

\section{Introduction}

A steady progress in the electrification of the economy is one of the main trends in the development of economies and power engineering. Despite the fact that the electric energy is less than the half of the current energy consumption, the aforesaid trend (with consideration of the urban population growth, new electronic technologies, the automated industries and others) steadily leads the global economy to the so-called "electric world" situation when the electricity is the dominant type of energy consumed $[5,13,15]$.

At present, one of the signs of the economy electrification is the development of electric motor vehicles with hybrid power units or completely electric ones for both the individual and commercial use and the public transport lines $[2,16]$. The key attention here is paid to the electric motor cars.

Many experts consider a technological break-through in the development of electric motor cars by 2020-2030 quite possible. It will be provided for by new light-weight and durables batteries (able to produce more than 5000 recharge cycles) as well as new electric motors (preferably without rare earth metals) and ultra-light construction materials $[6,7]$.

\footnotetext{
Corresponding author: shilovaLA@,mgsu.ru
} 
According to the plans of developed world countries supporting the production of electric motor vehicles, there will be 5 to $7 \mathrm{mln}$ of electric motor cars in the megalopolises to say nothing of the millions of hybrid cars. At first, the demand basis may be formed by the taxi companies, the logistic companies and others changing their fleets due to the support of their states [4].

The leading European countries and the USA declared their intention to abandon the use of internal combustion engines by 2050 . In Russia, at present, we also have taken some programmes on introduction of electric motor transport which are put into practice in some regions. Here, the analysis of possible engineering solutions for such projects as well as of their competitiveness with consideration of natural climatic conditions and other factors in very important.

An active use of electric motor transport is impossible without a developed batterycharging system, which should be efficient from point of view of both economy and power engineering, and which should be able to be installed into both the existing power engineering systems and the prospects ones. In this situation, the mass use of electric motor cars will cause the growth of total electric energy consumption, and it will require the introduction of new power plants. In the process of integration of electric motor cars into transport system in Russia, the question of the influence of battery-charging system on the existing power grid as well as on the power engineering services for the other consumers will be very important. It is also important to consider a possible use of renewable energy sources as additional capacities for battery-charging systems. Taking into consideration both the solar energy potential in Russia and the promising regions concerned, we may conclude that it is quite logical to use the solar energy for the battery-charging systems in southern and central RF regions.

The average electric motor power is 3 to $5 \mathrm{~kW}$ and more, the battery capacity is not less than 2 to $5 \mathrm{kWh}$ for hybrid cars and $20 \mathrm{kWh}$ and more for electric motor cars. It provides for a considerable increase in the demand for electricity and stimulates the development of the power system which acquires a new active consumer. On the other hand, the power system can use the batteries for some time periods and so to smooth the energy consumption peaks etc. [1]

The electric motor vehicles and renewable energy sources (RES) are the most promising technologies for the improvement of urban environment in megalopolises [3,5,10]. The motor transport is the main pollutant in cities. In our country, one of the most important unsolved problems is the development of the battery-charging system including local renewable energy sources efficiently integrated into the power grid $[2,8,9,14]$. The promising regions for the development of the battery-charging stations should be chosen; it will allow us to plan an efficient development of both the battery-charging system and the electric motor transport.

\section{How to choose the appropriate regions for the development of electric motor transport and battery-charging systems}

To promote such an unusual product for the consumers as the electric motor vehicle, it is necessary to choose the appropriate regions in the RF. Considering the special features of this motor transport type, we suggest the following criteria for the estimate of regions under consideration:

- average per capita income;

- number of private cars;

- air pollution due to the fossil fuel combustion;

- provision of the region with electric energy; 
- available local renewable energy sources.

The electric motor cars will be more expensive in the near future than the conventional motor cars, so the regions with a higher per capita income are preferable.

The RF regions with the highest wages are the Central region, the North-West one, the Urals and the Far-East one [19]; the RFsubjects with higher wages are Moscow, St.Petersburg, Khanty-Mansi autonomous region-Yugra, Moscow Region, Tatarstan autonomous republic. The aforesaid regions have rather developed economies. The top ten rigions also include Yamal-Nenets autonomous region, Tyumen region, Sakhalin region, Samara region and Bashkortostan autonomous republic.

The introduction of a new product into the market requires a certain critical demand volume determined by the economic expediency of the process. Ceteres paribus, the estimated demand volume for the motor transport with "zero emission" will be proportional to the number of motor cars in the region. Therefore, the regions with the largest motor car fleets are preferable.

The motor car fleet in Russia includes 39349300 cars ("Avtostat Info" Co., $01.01 .2015)[18,20]$.

The number of private motor cars in Russia is calculated as a specific parameter "number of motor cars for 1000 people". At the beginning of 2015 this parameter was equal to 274 (without Crimea) in comparison with 258 an year earlier (6.2\% year's increase). Thus, the country motorization goes on despite the economic crisis caused by international punitive sanctions and the reduction of oil price. The Central federal region has the largest car fleet ( $30 \%$ with the $6.2 \%$ year's increase), the Volga region has the second largest one ( $20.1 \%$ with the $7.6 \%$ year's increase). The top ten regions are presented in Fig.1.

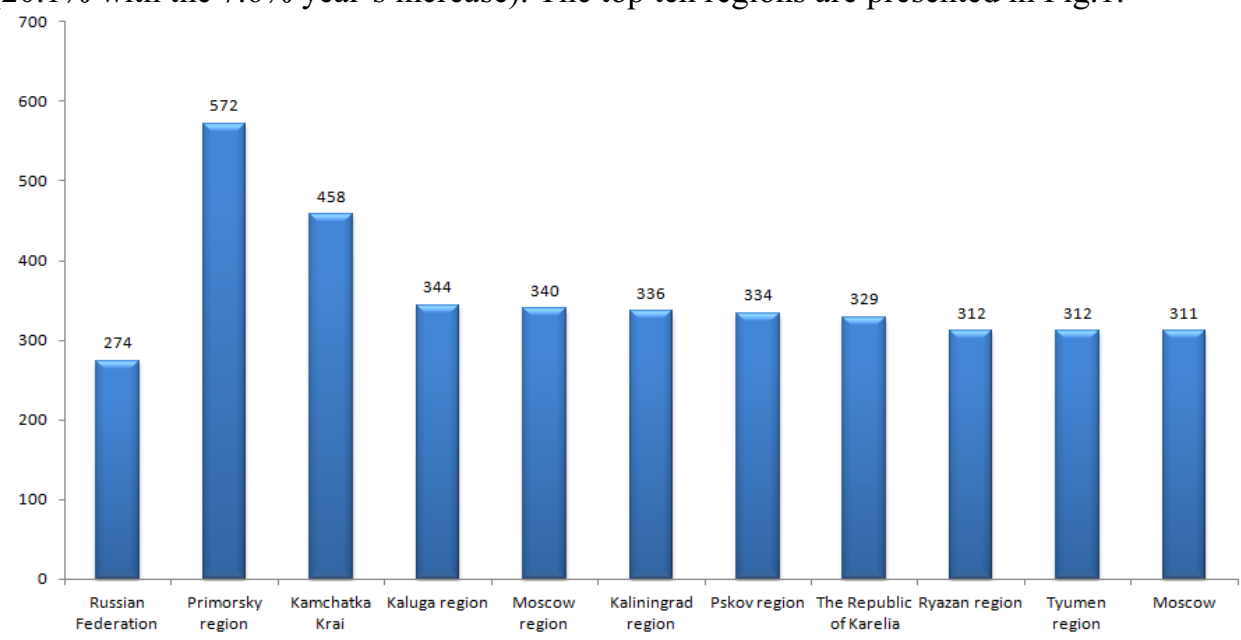

Fig.1. The RF regions with the highest values of the "number of motor cars for 1000 people' in 2014 [18].

The motor transport contributes much to the air pollution, and its improvement can play a considerable role in reduction of air pollution. In regions with high air pollution levels, the vehicles with "zero emission" will be welcome by both the population and the local authorities.

The estimated mass of the pollutants released into the air is not quite informative as it is not proportional to the pollutant concentration in megalopolises and large industrial centres. The data on air pollution in the regions are necessary, but this statistics in beyond the scope of this study.

It is expedient to estimate the fuel expenditures as they considerably determine the total emission of greenhouse gases. On account of the quotas on greenhouse gas emissions, the 
electric motor cars may be considered as a means of reduction of these emissions due to the state subsidies for the purchase of vehicles with "zero emission".

According to the "Autostat Info" Co. [17], 15 largest regions in Russia consume 47\% of the fuel. The other 68 regions consume $53 \%$ of that. The European part of the country consumes more than $70 \%$ of the fuel. The regions with the highest consumption of fossil fuels: Moscow (8.36\%), Moscow region (5.58\%), Krasnodar region (3.81\%), St.-Petersburg (3.42\%), Primorsky region (3.12\%), Rostov region (2.77\%), Tatarstan (2.68\%), Sverdlovsk region $(2.67 \%)$, Chelyabinsk region $(2.21 \%)$, Samara region $(2.19 \%)$.

The electric energy is relatively cheap, and the maintenance of electric motor cars is cheaper as compared with conventional motor cars. However, the mass use of electric motor cars may cause a considerable increase in the maximum electric load in the region, and it would require either the introduction of additional electric generators or the improvement of carrying capacity of power systems. Both variants are rather expensive, and they may be rejected by the local authorities.

Several regions already have considerable negative energy balance due to the everincreasing consumption of electric energy by both the private households and the industry. So the preference should be given to the regions with positive or slight negative electric energy balance. An exception may be the regions with irregular daily schedule of electric energy consumption, as the reserve energy can be used at battery-charging stations.

The data on production and consumption of electric energy in the RF regions are available in the open Rosstat statistics issues [21].

Top ten RF regions with positive electric energy balance: Saratov region, Tver region, Leningrad region, Kursk region, Smolensk region, Krasnoyarsk region, Kostroma region, Stavropol region, Irkutsk region, Amur region.

Among the regions with decentralized power supply, it is necessary to determine the regions with considerable renewable energy resources and to evaluate their potential use at the battery-charging stations.

Fig. 2 presents the engineering capacity of the RF regions with the highest local wind and solar energy resources. The engineering capacity of the use of renewable energy sources is the wind and solar energy available for the conversion into the electric energy in compliance with the environment protection regulations [12]. This criterion is very important for the development of battery-charging systems for electric motor cars in decentralized regions.

The use of renewable energy sources at battery-charging stations in the RF regions with developed power systems may be expensive and inefficient. In regions with dominant nuclear power plants and hydroelectric power plants, the environmental benefits may be questionable as these technologies themselves do not produce considerable heat energy emissions. Moreover, the NPP have the surplus energy at night, when the energy consumption in less. At the same time, the renewable energy sources may produce considerable environmental effect in the regions with dominant thermal power plants and even economic effect in the regions with undeveloped power systems. 


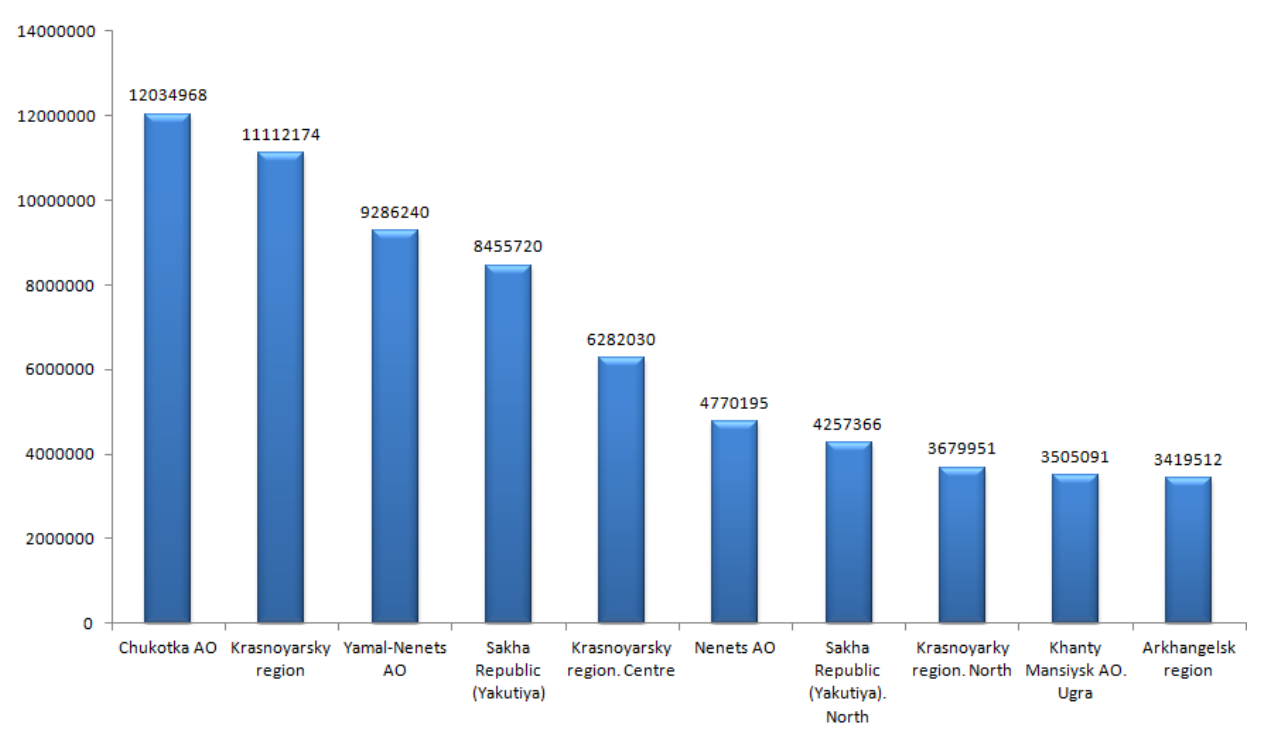

Fig.2. The RF regions with the highest local wind and solar energy resources, billion $\mathrm{kWh}$ [11].

On the basis of the aforesaid study, we can conclude that the most promising regions for the development of electric motor vehicles and the battery-charging systems are Moscow, Moscow region, St.-Petersburg and Leningrad region which head the top ten regions with respect to the aforesaid parameters. The following regions are good for these projects as well: Kaliningrad region, Krasnoyarsk region, Primorsky region, Sakhalin region, Tyumen region, Tatarstan autonomous republic. The most promising for the use of renewable energy sources at the battery-charging stations are the following regions: Yamal-Nenets region, Sakha region (Yakutiya), Krasnoyarsk region and Arkhangelsk region.

\section{Conclusion}

Despite the success in the field of development of autonomous electric motor transport, one of the main problems in the field will be the undeveloped battery-charging system in Russia. This problem is rather an economic one than a technological one. There are still not many battery-charging service users, and so the investors are reluctant to invest into the projects concerned, and the sale of electric motor vehicles is growing slowly due to the lack of battery-charging services.

The use of electric motor vehicles promises both benefits and some expenses. Currently, for the end users, the lower operating costs do not compensate a higher cost of electric motor vehicles. In this situation, the encouragement of introduction of electric motor vehicles may be carried out not only due to the state subsidies to the purchase of electric motor cars (as is the case in the EU countries) but also due to a professional planning and the investments into the development of an efficient system of battery-charging stations.

The electric motor vehicles help to diversify the fuel consumption balance reducing the dependence on oil products. The electric energy in our country is not expensive, and the production of electric motor vehicles may help to develop new high-tech industries, to create new working places and to increase the economic growth. In the long term, the use of electric motor vehicles will allow us to reduce the level of harmful emissions in the cities. The study based on a preliminary comparative analysis of the RF regions with respect to five indices (average per capita income, number of private cars in the region, air pollution level, provision of the region with power supply and the potential use of local 
renewable energy sources) allowed us to choose the most promising regions from the point of view of possible construction of battery-charging stations necessary for the use of electric motor vehicles with "zero emission". The most important of the aforesaid regions are Moscow and Moscow region. Ten more regions in Russia are promising as well. The use of renewable energy sources at the battery-charging stations will be expedient only in Northern and Eastern regions, where the most part of electric energy is produced at thermal power plants and the power systems are not properly developed yet.

The environmental effect of construction of battery-charging stations is obvious only for megalopolises. The total environmental effect will depend on the engineering characteristics of battery-charging stations, the charging speed, the climatic conditions of their operation, the type of energy generation (thermal, nuclear, hydraulic, etc.) and the fuel type. The various combinations of the aforesaid parameters in the process of the use of electric motor cars may result in both the reduction and the increase of the greenhouse gas emissions in the country. At the same time, the reduction of greenhouse gas emissions and the sale of quotas at the foreign market is nowadays the most obvious and simple way of monetary evaluation of the environmental effect of the development of electric motor transport.

The further studies will include a thorough analysis of daily and seasonal irregularity of the consumption of electric energy, applied to the possible use of the power reserves at the battery-charging stations. It is also necessary to determine some additional factors influencing the development of battery-charging systems with the use of renewable energy sources.

\section{References}

1. P.H. Andersen, J.A. Mathews, M. Rask, Energy Policy, 7(37), 2481-2486 (2009)

2. E. Azadfar, V. Sreeram, D. Harries, Renewable and Sustainable Energy Reviews, 42, 1065-1076 (2015)

3. A.R Bhatti, Renewable and Sustainable Energy Reviews, 54, 34-47 (2016)

4. M.A. Hannan, F.A. Azidin, A. Mohamed, Renewable and Sustainable Energy Reviews, 29, 135-150 (2014)

5. L. Liu, Renewable and Sustainable Energy Reviews, 51, 648-661 (2015)

6. S. Manzetti, Mariasiu, L. S. Florin, M.F.E. Manzetti, Renewable and Sustainable Energy Reviews, 51, 1004-1012 (2015)

7. I. Rahman, Renewable and Sustainable Energy Reviews, 58, 1039-1047 (2016)

8. S. Speidel, T. Bräunl, Renewable and Sustainable Energy Reviews, 40, 97-110 (2014)

9. K.M. Tan, V.K. Ramachandaramurthy, J.Y. Yong, Renewable and Sustainable Energy Reviews, 53, 720-732 (2016)

10. A. Verma, Energy, 86, 548-559 (2015)

11. T.I. Andreenko, T.S. Gabderahmanova, O.V. Danilova, Atlas of Russian renewable energy resources: scientific edition (MUCTR. Mendeleev, Moscow, 2015)

12. P.P. Bezrukikh, Russian renewable energy resources directory (Energia, Moscow, 2013)

13. V.V. Bushuyev, V.V. Timatkov, ELECTRO: electrical engineering, power engineering, 3, 2-5 (2012)

14. S.V. Kiseleva, O.S. Popiel, A.A. Tarasenko, International Scientific Journal for Alternative Energy and Ecology, 11(133), 16-24 (2013)

15. V.V. Timatkov, Energy policy, 6, 58-67 (2014)

16. V.V. Timatkov, V.V. Bushuyev, Electric transport as part of the electrical world. Facts and Forecasts (Energy, Moscow, 2015)

17. Information on https://www.autostat.ru/infographics/10178 
18. Market of passenger cars in Russia. The results of the 2014, trends and outlooks (, Autostat, Togliatti, 2015)

19. Information on http://www.gks.ru/free_doc/new_site/population/trud/srzarplata/t2.xlsx.

20. Information on http://avtostat-info.com/Article/130.

21. Information on http://www.gks.ru/wps/wcm/connect/rosstat_main/rosstat/ru/statistics/enterprise/indust rial 